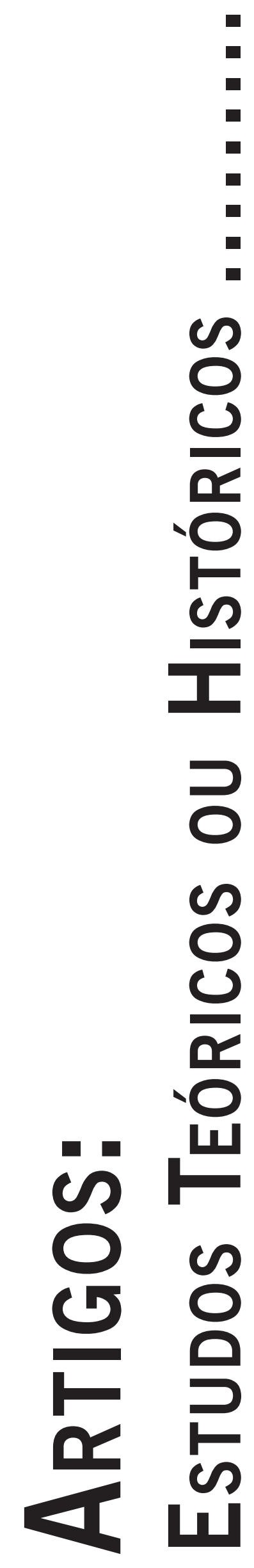




\title{
INFÂNCIA, FILOSOFIA DA EDUCAÇÃO E FENOMENOLOGIA: APROXIMAÇÕES NECESSÁRIAS
}

\author{
Childhood, Education Philosophy and Phenomenology: Necessary Approaches
}

Niñez, Educación Filosofía y Fenomenología: Enfoques Necesarios

Ana Maria Monte Coelho Frota

\begin{abstract}
Resumo: Este trabalho tem como objetivo propor o início de uma discussão entre a filosofia da educação, a fenomenologia hermenêutica e a infância. Parte da consideração de que a filosofia da educação tem avançado bastante nos estudos acerca da infância e da criança, apontando direções possíveis de ruptura com paradigmas alicerçados na modernidade. Avança, principalmente, na busca de construir uma aproximação com a hermenêutica heideggeriana, considerando alguns pontos de convergência entre as filosofias referidas. A partir de então, levanta alguns pontos de tangenciamento possível entre os pensamentos. Além disso, sabedora da ausência de uma discussão sobre a infância e a criança na obra de Heidegger, ausência justificada pela preocupação de Heidegger com a questão ontológica do sentido do ser, busca olhar para elementos ônticos que possibilitem reflexões inspiradas na filosofia hermenêutica, proporcionando uma maior compreensão da infância.
\end{abstract}

Palavras-chave: Fenomenologia Hermenêutica; Filosofia da Educação; Infância.

\begin{abstract}
This work aims to start a discussion between philosophy of education, phenomenology, hermeneutics, and childhood. It has as a starting point the consideration that philosophy of education has been doing a great progress in the studies about childhood and child, pointing to possible directions of rupture with paradigms supported in modernity. This paper seeks to build a closer relation with heideggerian hermeneutic, considering some points of approximation between the philosophies. From then on, it brings some possible points of tangency between the perspectives. Furthermore, knowing that there is a lack of discussion between childhood and child in Heidegger's work, justified by Heidegger's preoccupation with the ontological question of the sense of being, we attempt to look at ontological elements that enable reflections inspired in the hermeneutic philosophy, providing a better comprehension of childhood.
\end{abstract}

Keywords: Phenomenology; Philosophy of Education; Childhood

Resumen: Este trabajo tiene como objetivo proponer el inicio de una discusión entre la filosofía de la educación, la fenomenología hermenéutica y la infancia. Parte de la consideración de que la filosofía de la educación está muy avanzado en los estudios de la infancia y los niños, señalando las posibles direcciones de ruptura con los paradigmas a tierra en la modernidad. Avances sobre todo en la construcción de relaciones más estrechas con la hermenéutica de Heidegger, teniendo en cuenta algunos puntos de convergencia entre esas filosofías. Desde entonces, plantea algunos puntos de tangencia entre los pensamientos. También, y consciente de la ausencia de una discusión de la infancia y el niño en la obra de Heidegger, ausencia justificada por la preocupación de Heidegger con la pregunta ontológica del significado de ser, localizan los elementos que permiten reflexiones inspiradas en la filosofía hermenéutica, para promover una mejor comprensión de la infância.

Palabras-clave: Fenomenología; Filosofía de la Educación; Infancia

\section{Iniciando a conversa}

Vamos nos despreocupar com os resultados de nosso encontro. Simplesmente, encontremo-nos para ouvir outras vozes, para ouvir outras histórias. Para viajarmos. Sairmos daqui, de nosso lugar. (Pulino, Resistência e Criação na Formação de Professores)

A infância constitui-se, na contemporaneidade, numa categoria social, campo de estudo de diferentes disciplinas e olhares científicos. Tem se configurado como foco de discussões, debates e reflexões, intentando alargar sua compreensão. Hoje existe uma clareza muito grande, um movimento assumido amplamente, no sentido de considerar a criança um devir, um ser aberto às possibilidades. Ao mesmo tempo, a criança sai de um lugar de- finido anteriormente, como aquele ser incompleto e em processo de desenvolvimento, para outro lugar, habitado por uma compreensão mais aberta e prenhe de possibilidades (Frota, 2007). Nesta direção, Castro (2013) já nos alerta para uma linha de questionamento contemporâneo que desconstrói a diferença entre a criança e as outras categorias geracionais, tal como produzida pela perspectiva desenvolvimentista e evolucionista, característica do nosso tempo. O que está em estado nascente, assegura a estudiosa, "é justamente a pluralidade do devir, as possibilidades diversas e múltiplas de ser que são abandonadas ao longo do percurso da história de cada um” (p. 23). Seria algo, tal como afirma Larrosa (2013, p. 186), como “(...) devolver à infância, a sua presença enigmática e de encontrar a medida da nossa responsabilidade pela resposta, ante a exigência que esse enigma leva consigo”? 
Pretendo, pois, com este estudo, aproximar-me de uma compreensão possível da infância e da criança, tendo como fonte de inspiração a filosofia da educação ${ }^{1}$ para, com ela, e com alguns elementos da hermenêutica filosófica heideggeriana, abrir um diálogo inaugural acerca do tema. Sei que trago somente elementos iniciais, incipientes e insuficientes para a tarefa que me proponho. No entanto, é preciso começar. É necessário lançar-me nesta difícil tarefa para, quem sabe, poder contar com novos olhares e mãos.

Encontro-me com reflexões da filosofia da educação que servem de respaldo para questões que me inquietam e que podem se traduzir em indagações: poderá ser a infância um momento existencial para além do cronológico? Se assim o é, podemos nos pensar como seres possíveis de ter todas as idades ao mesmo tempo? Sem elementos para aprofundarmos estas questões, sigamos. A filosofia da educação traz uma contribuição muito importante aos estudos que têm sido feitos nesta seara: a criança precisa dizer-se. Além disso, para Kohan (2004, p. 131):

A infância pronuncia uma palavra que não se entende. A infância pensa um pensamento que não se pensa. Dar espaço a essa língua, aprender essa palavra, atender esse pensamento pode ser uma oportunidade não apenas de dar um espaço digno, primordial e apaixonado a essa palavra infantil, mas também de educar a nós mesmos.

Kohan (2004, 2007, 2010, 2011), Agamben (2005) e Larrosa (2013 e 2015) trazem a compreensão da infância como um tempo aberto ao atravessamento da experiência. Acenam com a possibilidade de se ver a criança como um radicalmente outro, rompendo de vez com sua representação como um ser da falta e da incompletude. Ao convocar tal debate, colocamo-nos diante de uma possibilidade existencial que ultrapassa a cronologia e o tempo linear, abrindo-nos à possibilidade de também nos relacionarmos com a infância a partir de um outro tempo, um tempo acontecimental, aiônico, uma vez que "a suposta linearidade e avanço do tempo e dos fatos enreda-se nos eventuais percalços que assinalam o reducionismo imposto por um modelo unívoco de temporalidade" (Castro, 2013, p. 28).

Finalmente, a partir da filosofia hermenêutica heideggeriana, partindo da sua ontologia e, numa tentativa de compreensão ôntica de algumas estruturas também ônticas, teço reflexões que me possibilitam uma aproximação de um diálogo possível com a infância, à luz desta inspiração. Apesar de Heidegger não se referir à criança ou

\footnotetext{
Trabalho com as ideias defendidas pelos filósofos Kohan (2004, 2007, 2010, 2011), Agamben (2005) e Larrosa (2013, 2015), que pensam a infância e a criança num movimento intitulado filosofia da educação, construído a partir das ideias de Foucault. Assim, a partir deste momento, ao me referir ao termo filosofia da educação, retorno meu pensamento a estes autores.
}

à Infância, pois apresenta uma ontologia do ser, falandonos somente do Dasein e do seu modo de ser-no-mundo, parece-me que rompe de vez com a ideia de temporalidade linear, que é o tempo que atravessa o ciclo de vida dos humanos, tal como apresentado na contemporaneidade, e na civilização oriental. Além disso, também defende questões importantes relacionadas ao tempo da técnica, inspirando uma possibilidade de crítica radical à categorização do ciclo vital.

Kohan (2007) apresenta a criança como um estrangeiro, como aquele ser que fala uma língua não domesticada, que rompe e transgride, que é capaz de se dizer algo de modo novo, inaugural. Fala da criança concreta, ôntica. Já Heidegger (1959/2012), se refere ao estrangeiro como aquele que se desprende, que se despede, caminhando por uma vereda diferente. Fala de uma ontologia. Refere-se à poesia. Pergunto-me, seria possível aproximar as perspectivas dos filósofos? Faz-se possível um diálogo fecundo entre a concretude da criança e da infância, pensada pela filosofia da educação, e a ontologia do ser, do Dasein heideggeriano? Será que Heidegger, ao afirmar que "o desprendimento é o lugar da poesia porque a harmonia dos passos ressoantes e iluminadores do estrangeiro inflama a travessia obscura dos que o seguem num canto em escuta" (p. 59), estaria pensando que a poesia reflete a fala do estrangeiro? E que o estrangeiro seria aquele que, como ele afirma, o que escuta o viandante: "um amigo ausculta o estrangeiro. Auscultando, o amigo segue o desprendido, tornando-se ele mesmo um viandante, um estrangeiro" (p. 57)?

Também para Heidegger (1959/2012) "a linguagem fala” (p. 9). Assim como usada para se comunicar, ela também pode nos conduzir a nós mesmos, levando-nos para o lugar de um modo de ser de nossa essência. Nas palavras de Heidegger, "recolher-se no acontecimento apropriador” (p. 9). Então, se a criança fala, como um estrangeiro que é, e ausculta como um viandante, como fazermos para escutá-la? E onde se encontra essa criança na nossa existência fática?

\section{O devir-criança ou um encontro mágico com a filosofia da educação}

(...) que a importância das coisas não se mede com uma fita métrica nem com balanças nem barômetros, etc. Que a importância de uma coisa há que ser medida pelo encantamento que a coisa produza em nós (Manoel de Barros, Poesia Completa)

A possibilidade de compreender a infância como um devir nos convoca para uma difícil tarefa: a desconstrução da categorização cronológica da existência humana e de sua caracterização unívoca. Uma tarefa por demais necessária, mas deixada para outro momento. Por agora, olhemos para a infância. Segundo esta opção de aborda- 
gem, a compreensão do devir-criança fez-se imperante: o devir-criança é um encontro entre um adulto e uma criança! ${ }^{2}$ Deste modo, “(...) aproxima os adultos da potencialidade infantil e, com isso, pode gerar novas perspectivas sobre a realidade, levando-nos ao questionamento de algumas certezas e nos conduzindo, enfim, a reflexões esclarecedoras" (Amorim, 2012, p. 177-78). A filosofia da educação fala de um tempo que não é o cronológico, e sim o aiônico. Nesta compreensão, é a existência concreta e presente que importa mais do que a cronológica. O tempo khronos, nesta perspectiva, perde seu reinado, dando espaço para o acontecimento, que não é o que sustenta a divisão da existência do homem em fases ou estágios que compõem o ciclo vital. É mesmo um tempo que possibilita uma experiência pessoal e intransferível, tempo esquecido na era da técnica.

Com relação à divisão do tempo humano em estágios, Oliveira (2012) assegura: essa é uma "tentativa de objetivar algo que nos escapa. Queremos nomear a experiência humana, ordená-la, classificá-la” (p. 180), pensamento que corrobora com minha reflexão. Seria mesmo um signo de uma época da técnica, eu diria. Na verdade, ao fazermos isso, corremos sério risco de perdermos a experiência e, com ela, a possibilidade de chegarmos a sermos o que somos (Larrosa, 2013). A experiência é vista como algo que coloca em risco a objetividade e a eficiência técnica da modernidade, sendo, por isso mesmo, temida e evitada.

Agamben (2005) e Larrosa (2015) parecem falar por mim ao considerar que o homem moderno foi expropriado da possibilidade de ter experiências na vida. Deste modo, a criança traz de volta esta viabilidade, por instaurar um tempo-espaço no qual ainda não é um ser que usa socialmente a linguagem, mas está sempre mergulhado nela. A infância seria, deste modo, um tempo que permite pensar que, para falar, não basta simplesmente aceder a uma língua sem fraturá-la. Socialmente, torna-se necessário transformar a linguagem em fala. Neste processo, a história é essencial. Assim, experiência e infância são essenciais para falar!

Para chegarmos a sermos o que somos, alerta Kohan (2011), é necessário fazermos uma ontologia crítica de nós mesmos, demandando que cheguemos às condições históricas e genealógicas que nos constituem. Se assim não o fizermos, corremos o risco de ficarmos somente com o que nos é ensinado a sermos. Seremos aquilo que constitui o horizonte dos tempos da técnica: um vir a ser³ ${ }^{3}$ já defi-

\footnotetext{
Pensar a infância através de um movimento de devir supõe fraturar diversas figuras da infância que povoam o imaginário do pensamento ocidental, fundadas numa visão linear da história e da linguagem, definindo-a como espaço da continuidade (descontinuidade) e da unidade/totalidade (pluralidade): a imagem bio-psico-social da infância (...) Essas concepções da figura da infância vinculam-se, respectivamente, a uma concepção da temporalidade histórica linear, homogénea, progressiva, e a uma concepção nostálgica do passado (Vilela, 2010, p. 56).

3 Nesta perspectiva, o vir a ser seria um desenvolvimento que cumpre o que é esperado e descrito como próprio dentro do ciclo vital e das fases desenvolvimentais.
}

nido anteriormente, com pouco espaço de transgressão e invenções. Fica clara a urgência de pensarmos a questão com relação à verdade que constitui os indivíduos em sujeitos do conhecimento; ao poder pelo qual nos constituímos como sujeitos atuantes sobre os outros; e, finalmente, a ética, por meio da qual nos constituímos como sujeitos morais. O homem contemporâneo foi expropriado da experiência, também acredita Larrosa (2015, p. 28): "É experiência aquilo que nos passa, ou que nos toca, ou que nos acontece, e, ao nos passar, nos forma e nos transforma. Somente o sujeito da experiência está, portanto, aberto à própria transformação". Muito ressaltada a ausência da experiência pelo homem moderno, ela é compreendida como um impedimento para uma existência rica e plena. Nesta direção, continua o filósofo:

(...) se chamamos existência a esta vida própria, contingente e finita, a essa vida que não está determinada por nenhuma essência e por nenhum destino, a essa vida que não tem nenhuma razão sem nenhum fundamento fora dela mesma, a essa vida cujo sentido se vai construindo e destruindo no viver mesmo, podemos pensar que tudo o que faz impossível a experiência faz também impossível a existência. (2015, p. 33)

A partir destas reflexões, a infância se deixa ver a partir de dois planos: do ôntico, do qual olho para a criança concreta, problematizando o lugar no qual ela tem sido colocada na contemporaneidade, submetida que é, ao "adultocentrismo" e à técnica. Por outro, do campo ontológico, do qual a compreendo como uma possibilidade de existência, capaz de romper com o tempo cronológico e com os estágios desenvolvimentais, podendo dizer-se em qualquer momento da sua vida.

Voltando à filosofia da educação, temos que a infância pode ser tomada como o nascimento de uma possibilidade de ruptura com a aridez e infecundidade modernas, afastando-se da compreensão única de que ela é um tempo da vida compreendido entre o nascimento e a entrada na puberdade. Inaugura, assim, a possibilidade de se poder ser criança na existência, sem marcação cronológica. A infância é estrangeira num mundo da técnica. Como tal, fala uma língua nova; pensa o que não se pensa; transita por onde não se costuma andar; inventa, cria, rompe. A infância vive num tempo que comporta o Kronos e o Aion. Não se regula pelo relógio, somente. Assim, não se esgota em si mesma e sim, no esvaziamento acontecimental e da experiência.

Com a filosofia da educação questiono o mito da infância como um tempo que se mede pelas horas. Duvido da crença na criança como um ser em processo de evolução, que se contrapõe ao adulto, acabado no seu processo de desenvolvimento. Reflito acerca do mito da criança que não fala, que não sabe, que ainda não é capaz. Considero que experiência e infância não antecedem cronologicamente à linguagem, sendo, de fato, condições da 
linguagem. Compartilho com a crença de que a criança fala! Conclamo a todos nós escutá-la na sua outridade.

A infância é aqui entendida para além da cronologia, da fisiologia, dos limites legais. É compreendida como aquela singularidade silenciada, que não pode ser assimilada pelo sistema. Como faz questão de frisar Kohan (2011), seria mesmo uma forma de subjetividade.

Essa forma de subjetividade, que chamamos de infância, não tem idade. Ela é emancipatória na medida em que abre as portas a uma experiência múltipla de nós mesmos. Na medida em que emancipa a própria infância de uma imagem de si mesmo que a apressa (...). Na medida em que ela é experiência, é inerentemente transformadora do que somos, sem importar a idade. (p. 249)

Trata-se, deste modo, de uma questão política: pensar por si mesmo. Não é questão de idade ou capacidade e, sim, de condição e de sentido. Adoto Kohan (2007), mais uma vez, para falar por mim:

A infância que afirmamos é uma dimensão ainda não suficientemente pensada da existência humana. É uma chance de assumir a descontinuidade como condição ontológica da existência, uma abertura dessa experiência ao imprevisto, ao que pode ser de outra forma, ao que ainda não sabemos e nem podemos. (p. 251)

A partir desta perspectiva, a infância deixa de estar associada à falta, à incompletude e insuficiência, convidando-nos a vê-la, escutá-la e (re)conhecê-la para além das características elencadas historicamente. Para tanto, a filosofia nos oferece uma possibilidade de olhar para a infância a partir de "outras temporalidades, que não estão sob a égide do tempo cronológico, fator de medição e quantificação da realidade, positivizada e delimitada pela palavra, pela escrita e pelo número" (Castro, 2013, p. 29).

A filosofia da educação nos convida a olhar a infância como uma possibilidade de inovação, de irrupção do pensamento e do porvir. Agamben (2005) é brilhante ao nos interpelar, chamando-nos a romper com a imagem da criança frágil, tímida e incompleta, passando a considerá-la condição de ruptura, experiência, transformação. Na busca de dar prosseguimento as minhas reflexões, passo agora a me debruçar sobre a fenomenologia hermenêutica heideggeriana e algumas pistas possíveis de proximidade com esta discussão.

\section{Heidegger: o que escuto no seu silêncio?}

Olhos de Criança onde o céu volta a encontrar a nudez das estrelas

(Jacobo Fijman)
Heidegger, em sua obra, diz pouco sobre a infância ou a criança. Somente afirma que a criança é um Dasein, um ser-no-mundo, vivente num mundo da técnica. Apesar do filósofo não se dedicar a essas reflexões, considero possível buscar uma aproximação entre a hermenêutica filosófica heideggeriana e a infância, caminho que ainda está muito pouco desvelado, inclusive para mim. Pensemos em alguns elementos.

Heidegger (1996/2008) refere-se à criança apontando para seu caráter de poder-ser. É, no entanto, uma referência insuficiente para pensarmos a criança e a infância. Cabe a nós fazermos esta aproximação. Feijoo e Feijoo (2015, p. 11) considera que, a partir da perspectiva heideggeriana,

a criança se constitui a partir do mundo fático que é o seu ser. É em um horizonte hermenêutico com a familiaridade que lhe é própria e na que cada um conquista o horizonte que torna possível agir. O existente segue orientações do mundo que é o dele.

Concordando com essa posição teórica, penso em caminhar mais um passo: dentro deste horizonte histórico que somos nós, como pensar a criança e a infância refletindo sobre sua determinação? Como a filosofia de Heidegger pode nos ajudar nesta tarefa tão espinhosa? Mais uma vez peço inspiração a Feijoo e Feijoo (2015): “(...) pretendemos conquistar aquilo que nos dará bases para poder pensar a criança sem nos perdermos na poeira dos possíveis nem de nos amalgamarmos ao aprisionamento dos necessários (p. 12).

Comecemos com Heidegger (1927/1995): Dentre as estruturas de possibilidades que fazem parte do humano, está o ser-no-mundo como a mais básica delas. Seguem-se a temporalidade, a espacialidade, o encontrar-se, o compreender e a linguagem. Ao Dasein é impossível ser, sem ser-no-mundo, que é sua constituição fundamental. Heidegger assegura que o homem é mundano, que ele é, sendo no mundo. O Dasein é ser-aí, é estar-aí-junto-com-os-outros. Ele é junto aos outros, habitando o mundo, cuidando de ser. Existe, pois, uma inevitável ligação entre o homem e o mundo. Esta compreensão é pré-ontológica, pois que construída de forma irrefletida e inquestionada, tornando-se aquilo que define o modo de ser do Dasein. Para Costa (2015, p. 70), “(...) esta historicidade elementar do ser-aí, na maior parte das vezes, permanece escondida dele mesmo, que a partir de então toma a si e, consequentemente, seu horizonte histórico como absolutos”. Em Ser e Tempo, Heidegger pretendeu abalar as certezas de uma tradição metafísica e instaurar a possibilidade de pensar para além destas amarras. E conseguiu!

Seguindo nesta direção, surge uma primeira possibilidade de reflexão: O que é a infância? Quem é criança? Como é ser criança? Perguntas abertas, e que trazem consigo algumas rupturas com conhecimentos cristalizados, 
construídos a partir de matrizes também metafísicas. Na nossa tradição histórica a criança é pensada e compreendida como habitando um tempo da infância, delimitada por uma temporalidade cronológica; tem suas características descritas de modo naturalizados e biologizantes; tem seu tempo organizado categorialmente, juntamente com outros estágios, ou fases, como a adolescência, adultez e velhice. É bem verdade que Heidegger não nos falou sobre a criança. Mas também é correto afirmar que suas reflexões podem nos ajudar a pensar sobre ela. Ao dizer que "embora experienciado e reconhecido pré-fenomenologicamente, o ser-no-mundo se torna invisível por via de uma interpretação ontologicamente inadequada” (1927/2015), o filósofo pode ser compreendido como alertando para a invisibilização das possibilidades existenciais da criança, ao ser esmagada dentro de uma fase cronológica, universal, biologizante, tornando-se um mero vir-a-ser. Escutemos o que ele nos fala:

Uma analítica da presença constitui, portanto, o primeiro desafio no questionamento da questão do ser. Assim, torna-se premente o problema de como se deve alcançar e garantir a via de acesso à presença. Negativamente: a esse ente não se deve aplicar, de maneira construtiva e dogmática, nenhuma ideia de ser e de realidade por mais evidente que seja. Nem se devem impor à presença categorias delineadas por tal ideia. Ao contrário, as modalidades de acesso e de interpretação devem ser escolhidas de modo que este ente possa mostrar-se por si mesmo e em si mesmo. (1959/2012, p. 54)

No horizonte de nossa tradição, como a criança pode dizer-se se ela não tem sua fala escutada? Se ela é considerada um ser em processo de evolução, para se tornar completa e capaz, somente como um adulto? Pela tradição, principalmente a partir do olhar da psicologia desenvolvimentista, a criança é definida principalmente pela falta, pela ausência de capacidades e em evolução para se tornar adulta. Não estaria Heidegger (1927/2015) falando de coisas assemelhadas aos filósofos da educação quando afirma:

Todavia, a própria significância, com que a presença sempre está familiarizada, abriga em si a condição ontológica da possibilidade de a presença, em seus movimentos de compreender e interpretar, poder abrir significados que, por sua vez fundam a possibilidade da palavra e da linguagem? (p. 138)

Se Kohan afirma que a criança fala, Heidegger diz que o Dasein abriga em si a possibilidade de falar. E o Dasein criança, quem seria ele? Certamente um ser-aí, não definido pelo tempo cronológico somente; um ser vivente. Um estrangeiro no mundo? Sem respostas para tais questões, sigo com Heidegger.
Com a ideia de co-pertencimento entre homem e mundo, Heidegger fala do acontecimento do Dasein, desde sempre atravessado pelo mundo. Além disso, a vida é dada ao homem como possibilidade, sob determinadas condições, não existindo qualquer substrato anterior, que lhe dê qualquer segurança primeira. O Dasein é um devir, significando que tem que cuidar de si. A responsabilidade pelo cuidar de ser é condição humana, básica e intransferível. Acontece que, a maior parte das vezes, e escondido pelo projeto da técnica, a pessoalidade, a experiência, a possibilidade de falar uma linguagem poética, estrangeira, são quase totalmente aniquiladas na decadência da impropriedade.

A era da técnica faz um malogro com as possibilidades de ser, entregando um modelo a ser seguido. As possibilidades de trazer a marca pessoal desaparecem, para valorizar a eficácia do projeto social. Com inspiração na ideia da criança como aquele que é capaz de falar, defendida pela filosofia da educação, penso, ontologicamente, no Dasein-criança como possibilidade de dizer, apropriando-se de uma fala mais originária. Aí, retornando para o campo ôntico, a infância poderia ser vivida em qualquer momento existencial, pois que seria determinada por outros aspectos, que não a cronologia ou a biologia.

Seria a criança um estranho? No dizer de Heidegger (1959/2012, p. 30), "estranho significa comumente o que não é familiar, o que não nos diz respeito, mas sobretudo o que nos pesa e inquieta”. A criança se inaugura no mundo, onticamente falando. Aliás, ela e mundo se inauguram, ao mesmo tempo, fenomenologicamente. Deste modo, ela inaugura, dentre as possibilidades, a de invenção, de transgressão. Ela incomoda, amedronta, pelo potencial transgressor que traz consigo. Ao mesmo tempo, o Dasein-criança, enquanto ontologia do ser, ao se fazer estrangeiro no mundo, pode falar uma língua estranha, ser um poeta, podendo apropriar-se de algo originário, próprio, experiencial? Aqui falo da criança como condição de ser no mundo. Porém, como diz Heidegger (1927/2012, p. 185), "o impessoal é e está no modo da consistência do não si-mesmo e da impropriedade”. Deste modo, a criança pode ser compreendida como um modo de ser que desvela uma possibilidade de ruptura, inauguração, transgredindo a impropriedade? Talvez sim, considerando o que afirma Heidegger (1927/2015):

se já o ser da convivência cotidiana que, do ponto de vista ontológico, parece vizinho ao ser simplesmente dado, é diferente em princípio, então não se pode, de forma alguma compreender o que é propriamente si-mesmo como algo simplesmente dado. O ser do que é propriamente si-mesmo não repousa num estado excepcional do sujeito que se separou do impessoal. Ele é uma modificação existenciária do impessoal como existencial constitutivo. (p. 188)

Assim como acontece com relação à inspiração que recebemos da filosofia da educação, que nos vem nos pla- 
nos ôntico e ontológico, algo semelhante, parece acontecer com Heidegger: A partir dele, inspirada na sua ontologia fundamental, critico a categorização na qual a criança é posta, uma vez que não é possível uma compartimentalização do Dasein! Além disso, por se guiar por um tempo diferente do cronológico, um tempo acontecimental, a ontologia heideggeriana não pode compreender o Dasein limitado por idade ou características biológicas, somente. Contam muito mais a experiência e a facticidade. Deste modo, indagamo-nos: se pensamos a infância como um tempo de rupturas e abertura de possibilidades, tal qual sugerem Kohan, Larrosa e Agamben, podemos imaginar o Dasein habitando um tempo, aqui denominado de infância, a partir do signo da transgressão, do pensamento que medita, da apropriação de uma fala originária? Se isso for possível, torna-se inevitável questionar o formato com que a infância e a criança são apresentadas na contemporaneidade, e as derivações que daí são tomadas, como verdades absolutas.

Falamos de uma criança, Dasein, que desvela um modo de ser. Sua temporalidade é outra, que não somente a cronológica. Isso coloca a possibilidade de ela se fazer presente por toda a existência. Falamos aqui de um espaço e de um tempo, de um modo de estar no mundo, não linear, constitutivos do ser-aí, o que impede que o Dasein seja tomado como um ente simplesmente dado.

Heidegger (1987/2001) explicita uma subjetividade constituída na era da técnica. Deixa perceber como a técnica provoca no homem um modo peculiar de ser. A partir desta tradição, a criança se encontra um passo atrás do adulto, caminhando para um vir-a-ser-adulto. Mas, para além desta possibilidade, que mais ela pode ser?

$\mathrm{Na}$ verdade, queremos acreditar, que a infância é a condição de ser afetado que nos acompanha a vida toda. $\mathrm{O}$ dito e o não dito, a falta de palavras, a ausência de voz (in-fans), nos afetos abertos e ampliados. Deste modo, fenomenologicamente, o Dasein-criança parece referir-se ao novo, às possibilidades transgressoras, seja no plano da ontologia, seja no campo da onticidade.

\section{Inventando: quem conta um conto acrescenta um ponto}

(...) O menino entrega ao mundo O dom da sabedoria Que nasce do coração. Porque é do amor e da infância Que o mundo tem precisão (Thiago de Melo - Faz escuro, mas eu canto)

Quero finalizar estas reflexões pensando em um aspecto que considero fundamental na fenomenologia hermenêutica: a questão da indissociabilidade homem-mundo. Heidegger defende a existência de uma ligação inevitável entre homem e mundo. O Dasein, afirma, é ser-no-mun- do-junto-com-os-outros. E nosso tempo, nosso mundo contemporâneo, é moldado pelo tempo da técnica. Deste modo, a partir da sua análise em Ser e Tempo, o homem é tecido a partir de um modo de ser que tem como paradigmas objetividade, racionalidade, mecanicismo, individualismo.

A Filosofia da educação, aqui apresentada a partir de Kohan, Larrosa e Agamben, corrobora para esta análise, afirmando, dentre outros elementos, que no tempo da técnica a experiência foi suprimida da nossa existência, retirando do homem a possiblidade de se aproximar de algo que lhe seja comum. A falta da experiência impede a ruptura e negação do domínio paradigmático do tecnicismo, marca predominante do projeto modernista. Acredito, pois concordo com esta perspectiva, que a infância, por ser um tempo no qual a fala estrangeira é existente, aparece como uma possibilidade de constituir-se como uma rota de fuga, aberta para o exercício de múltiplas possibilidades.

Como segundo elemento de análise trago, a partir de Heidegger, a singularização e propriedade humana. Compreendo, a partir dele e da filosofia da educação, que nosso tempo contemporâneo tenta retirar do homem o sofrimento existencial, a angústia, a dúvida, o trabalho demorado e artesão de construção da própria vida, afastando as distintas possibilidades de experiência. À criança é negada a possibilidade de ser por si mesma, sendo vista como um ser incompleto, um ser em vias de se tornar um adulto. Deste modo, ela está sempre atrás do adulto, pois caminha para se tornar um. É um vir-a-ser. A Filosofia da educação propõe que a criança assuma seu lugar de voz, podendo falar e se dizer, no campo ôntico. No dizer de Kohan, a infância resiste aos movimentos concêntricos e totalizantes. No campo ontológico, a criança seria uma possibilidade de - na estrangeiridade -, conquistar uma língua mais própria. Enquanto ontologia do ser, o Dasein pensado ônticamente, a partir desta sugestão, seria um modo de ser meditante, transgressor, singular?

Finalmente, o terceiro elemento que quero trazer para estas considerações é a questão da temporalidade. A classificação dos estágios do desenvolvimento é centrada no tempo cronológico. Para Heidegger, a temporalidade é uma condição de ser. Heidegger fala de um tempo que não é o kronos e sim o aiôn. Assim, o que é levado em conta prioritariamente é o tempo existencial, acontecimental, e o foco da experiência não é o tempo linear. Semelhante ao que pensa a filosofia da educação: o tempo da infância não é o da idade cronológica e sim o tempo acontecimental.

A partir destas reflexões, podemos pensar a infância como um modo de ser marcado pela afetação, pela possibilidade de falar uma língua estrangeira, por poder viver mais livremente a experiência. A infância, então, pode vir a ser compreendida como um tempo existencial, rompendo com a determinação cronológica, tão cara para a era da técnica. Ainda nesta linha de pensamento, torna-se possível pensar que podemos habitar e sermos habitados 
pela infância, que pode ser acessada em qualquer tempo da existência. Sermos crianças, portanto, seria possibilitado por uma ruptura com o vir-a-ser e abertura ao devir; pela experiência resgatadora, que nos possibilitaria uma conquista de um modo de ser mais próprio.

\section{Referências}

Agamben, G. (2005). Infância e História - destruição da experiência e origem da história. Belo Horizonte: Ed. UFMG.

Amorim, I. F. (2012). O pensamento unidimensional e as concepções de infância: reflexões sobre possibilidades de resistência. In: P. Oliveira, P. \& W. Kohan (Orgs). Biopolítica, Escola e Resistência - infâncias para a formação de professores (p. 171-178). Campinas: Alínea.

Barros, M. (2010). Poesia Completa. São Paulo: Leya.

Castro, L. R. (2013). O Futuro da Infância e outros escritos. Rio de Janeiro: 7 Letras.

Costa, Paulo. (2015). Da filosofia à clínica psicológica: uma experiência malograda de acolhimento atento e atmosfera permeável na clínica. In: A.M.L.C. Feijoo \& M. Protasio (Orgs). Situações Clínicas I - analises fenomenológica de discursos clínicos (p. 67-96). Rio de Janeiro: Edições Ifen.

Feijoo, A. M. (2011). A Cínica psicológica infantil em uma perspectiva existencial. Revista da Abordagem Gestáltica, 17 (2), p. 185-192.

Feijoo, A. M. \& Feijoo, E. L. (2015). Ser Criança - uma compreensão existencial da experiência infantil. Rio de Janeiro: Editora Ifen.

Frota, A. M. (2007). Diferentes concepções da infância e da adolescência: a importância da historicidade para sua compreensão. Estudos e Pesquisas em Psicologia (UERJ), 7 (1), 147-170.

Heidegger, M. (2008). Introdução à Filosofia. São Paulo: Editora Martins Fontes (Original publicado em 1996).

Heidegger, M. (2015). Ser e Tempo (vol. 1 e 2). Petrópolis: Vozes (Original publicado em 1927).

Heidegger, M. (2012). A Caminho da Linguagem. Petrópolis, RJ: Vozes/Bragança Paulista, SP: Editora Universitária São Francisco (Original publicado em 1959).

Heidegger, M. (2001). Seminários de Zollikon. São Paulo: Educ/ Petrópolis: Vozes (Original de 1987).

Kohan, W. (2004). Lugares de infância. Rio de Janeiro: Ed. D.P\& A.

Kohan, W. (2007). Infância, estrangeiridade e Ignorância - ensaios de filosofia e educação. Belo Horizonte: Autêntica.

Kohan, W. (2010). Devir-Criança da Filosofia. Belo Horizonte: Autêntica.

Kohan, W. (2011). Infância. Entre Educação e Filosofia. Belo Horizonte: Autêntica.
Larrosa, J. (2013). Pedagogia Profana - dança, pirueta e mascaradas. Belo Horizonte: Autêntica Editora.

Larrosa, J. (2015). Tremores - escritos sobre a experiência. Belo Horizonte: Autêntica.

Oliveira, P. (2012). Experiência Humana: infância e educação. In: L. Pulino, L \& S. Gadelha (Orgs). Resistência e Criação na Formação de Professores (p. 187-197). Campinas: Ed. Alínea.

Vilela, E. (2010). A Infância entre as ruínas. In: P. Pagni \& R. Gelamo (Orgs). Experiência, Educação e Contemporaneidade (p. 51-65). Marília: Ed. Poiesis.

Ana Maria Monte Coelho Frota - Graduada em Psicologia e Mestre em Educação pela Universidade Federal do Ceará, com Doutorado em Psicologia Escolar e do Desenvolvimento Humano pela Universidade de São Paulo. Terminou estágio pós-doutoral na Universidade Federal do Rio Grande do Norte em 2017. Atualmente é professora associada da Universidade Federal do Ceará, lotada no Departamento de Economia Doméstica. Vinculada ao Núcleo de Estudos e Pesquisas sobre Gênero, Idade e Família (NEGIF), Núcleo de Desenvolvimento da Criança (NDC) e ao Núcleo de Linguagem Desenvolvimento e Educação da Criança (LIDELEC) do Programa de Pós-graduação em Educação Brasileira da Universidade Federal do Ceará. Atua como supervisora clínica no curso de Psicologia da UFC, na área da psicologia fenomenológica-existencial. Endereço Institucional: Endereço: Av. Antônio Sales, 2367, ap. 401 - Dionísio Torres. CEP 60135-101 - Fortaleza - Ceará. Email: anafrota@ufc.br

Recebido em 22.06.2016

Primeira Decisão Editorial em 03.12.2016

Aceito em 02.08.2017 